\title{
Journal of Bangladesh Agricultural University
}

Journal home page: http://baures.bau.edu.bd/jbau, www.banglajol.info/index.php/JBAU

\section{Inhibitory effect of Zingiberaceae essential oils against Conopomorpha cramerella (Snellen) Lepidoptera: Gracillariidae}

\author{
B. Saripah ${ }^{1,2}$, M. L. S. Noor Hajjar ${ }^{2}$, A. Alias ${ }^{1}$, A. Zhang ${ }^{3}$ \\ ${ }^{1}$ Malaysian Cocoa Board, Kota Kinabalu, Sabah, Malaysia \\ ${ }^{2}$ Crop Protection Research Group, Faculty of Plantation and Agrotechnology, Universiti Teknologi MARA, Selangor, Malaysia \\ ${ }^{3}$ Invasive Insect Biocontrol and Behavior Laboratory, 10300 Baltimore Avenue, Beltsville, MD 20705-2350, USA
}

\begin{tabular}{|c|c|}
\hline ARTICLE INFO & Abstract \\
\hline $\begin{array}{l}\text { Article history: } \\
\text { Received: } 01 \text { June } 2019 \\
\text { Accepted: } 31 \text { August } 2019 \\
\text { Published: } 30 \text { September } 2019\end{array}$ & \multirow{4}{*}{$\begin{array}{l}\text { Zingiberaceae (Order: Zingiberales) is recognized as the essential herbaceous species in the tropics. } \\
\text { Several species of Zingiberaceae have shown potential in managing some Lepidopteran and Dipteran } \\
\text { pests. Currently, there is no report in Malaysia explores the potential use of Zingiberaceae in managing } \\
\text { cocoa pests, particularly the Cocoa pod borer (CPB), Conopomorpha cramerella. The study was } \\
\text { conducted to evaluate the potential of Zingiberaceae as an adult emergence inhibition of } C \text {. cramerella } \\
\text { using three locally grown species in Malaysia; Alpinia galanga (galanga), Curcuma longa (turmeric), } \\
\text { and Zingiber officinale (ginger). Different ages of the CPB pupa (Days } 1,2,3,4 \text {, and 5) were selected } \\
\text { and were sprayed with Zingiberaceae essential oils (EOs). Pupa was sprayed with EOs at four different } \\
\text { concentrations; } 100,200,400 \text {, and } 800 \mathrm{ppm} \text {. Observations were carried out after } 5 \text { to } 7 \text { days, where the } \\
\text { percentage of the unhatched pupa and healthy adult was recorded. The percentage of the deformed adults } \\
\text { were examined based on the abdomen, the antenna, the wings, and overall deformities. The study was } \\
\text { repeated four times for each EOs. Results denoted that the percentage of the unhatched pupa was the } \\
\text { highest at } C \text {. longa ( } 49.75 \% \text { a) and significantly different (p }<0.05 \text { ) with A. galanga ( } 48.00 \% \text { b), Z. } \\
\text { officinale ( } 40.97 \% \text { c) and control treatment ( } 13.59 \% \text { d). The highest healthy adult emergence was } \\
\text { recorded under the control treatment ( } 75.77 \% \text { a), and significantly different with all Zingiberaceae EOs. } \\
\text { The overall results denoted that most of the deformities occurred after pupa were treated with the } \\
\text { Zingiberaceae EOs at high concentrations ( } 400 \text { and } 800 \text { ppm), and engaged with the body and wing } \\
\text { deformities. The symptom of adult deformities after treating with EOs may indicate the potential of } \\
\text { Zingiberaceae as an adult emergence inhibitor of } C \text {. cramerella, and can be possibly used for the } \\
\text { development of Zingiberaceae based botanical pesticide in the future. }\end{array}$} \\
\hline $\begin{array}{l}\text { Keywords: } \\
\text { Cocoa pod borer, } \\
\text { Alpinia galanga, } \\
\text { Curcuma longa, } \\
\text { Zingiber officinale, } \\
\text { Zingiberaceae }\end{array}$ & \\
\hline $\begin{array}{l}\text { Correspondence: } \\
\text { B. Saripah } \\
\square \text { : sari@koko.gov.my }\end{array}$ & \\
\hline & \\
\hline
\end{tabular}

Copyright $\odot 2019$ by authors and BAURES. This work is licensed under the Creative Commons Attribution International License (CC By 4.0).

\section{Introduction}

Cocoa, Theobroma cacao (Linnaeus) (Malvales: Sterculiaceae) is an important crop that widely planted in the humid tropical regions, and subjected to be infested by a wide range of pests. Number of fifteen insects (mosquito bug, bee bug, cockchafers beetles, branch borer, mealybug, bagworms, aphids, grasshopper, shothole borer, cocoa white grub, husk borer, shoot borer, cocoa pod borer and thrips) were recognized as an essential pest infested cocoa plantation either at the nursery, young or mature tree (Lee et al., 2013). Among all pests, the Cocoa pod borer (CPB), Conopomorpha cramerella Snellen (Lepidoptera: Gracillariidae) a tiny moth becomes a significant threat to the Southeast Asia cocoa growers. $C$. cramerella female is capable of laying eggs from 40 to 100 and has the potential to lay more than 300 eggs during their maturity stage (Lee et al., 2013). Neonate larva of $C$. cramerella bore into the pod and move around inside, feed within the placenta, causing the development of damaged or clumped beans, thus reducing their quality and weight (Saripah, 2012). The larva generally mines and feed within the placenta, mucilage and sometimes testa, leaving behind galleries filled with brownish frass. The entire larval stage takes 14-18 days to complete, with 4-6 instars (Azhar, 1990). Subsequently, the larva tunnels out through the pod wall and leave a sign of exit holes. Due to their cryptic behaviour, which spending their entire larval stages within the pod, therefore controlling this stage is

\section{Cite this article}

Saripah, B., Noor Hajjar, M.L.S., Alias, A. and Zhang, A. 2019. Inhibitory effect of Zingiberaceae essential oils against Conopomorpha cramerella (Snellen) Lepidoptera: Gracillariidae. Journal of Bangladesh Agricultural University, 17(3): 349-354. https://doi.org/10.3329/jbau.v17i3.43210 
impossible. Mature larva emerged from the cocoa pod for pupation, immediately constructing the silken cocoon that enclosed their entire body part. Pupation occurs outside the pod within the oval-shaped silken cocoon and usually found intact on the dry cocoa leaves, green leaves, or on the pod surface (Saripah et al., 2019). Pupa tends to be more exposed to treatments or management approaches compared to the larva stage, especially during their early pupa emergence. Completion of the pupation stage usually takes 6 to 8 days. With the ability to regenerate 10 to 12 times a year, crop loss to farmers can be substantial. Continuous infestations may cause an unacceptable level of damage, influenced by the feeding and oviposition preferences for pods (Saripah, 2014). The infestation of C. cramerella occurred where developed cocoa beans were hardened and clumped together. Losses expected to be higher in smallholder's crops, due to a lack of knowledge about pest management, finance, as well as the manpower (Alias, 2011).

Diverse control attempts have been undertaken to manage the infestation of $C$. cramerella. Three decades after the first arrivals, biweekly prophylactic treatment with chemical insecticides was considered as one of the most effective approaches; even the cost can be considered high (Alias, 2011). However, recent studies conducted denoted that the combination of complete management practices was proven effective in reducing $C$. cramerella infestation. The complete management practices, including schedule insecticide spraying, pruning, fertilization, and weekly pod harvesting (Saripah and Alias, 2016). Mitigation technique must be promoted; however, the management must be feasible, easy to understand, less technical, safe to the environment and health, yet efficient must be taken into consideration.

The risk of resistance mechanism towards insecticide due to prolonged use in the cocoa plantation is higher with excessive usage of chemicals. Chemical insecticides must be suggested as a last resort; therefore, an effort is warranted to find alternatives to currently used insecticides. There is a need to assess some indigenous botanical plants, especially those with a presumably better potential for extension (Tounou et al., 2011). Many plant products and chemicals may play a role as oviposition deterrent, insect repellent, antifeedant either as larvicidal, pupicidal or adulticidal activities. Such plants, in addition to their inherent pesticide effectiveness, must be rustic, perennial and easily cultivated. Parkash and Rao (1997) cited that more than 800 species pose insecticidal and repellent, anti-feeding effects were used in agriculture, and this will offer more variety for plant selection in the future.

With more than 1,000 species recorded, Zingiberaceae (Order: Zingiberales) is one of the largest families in the plant kingdom. There are approximately 1,000 of the known species of the Zingiberaceae, obtained from 52 genera (Wohlmuth, 2008). Zingiberaceae plant will bear several horizontal or curved rhizomes when mature, which are again branched. Alpinia galanga (galanga), Curcuma longa (turmeric), and Zingiber officinale (ginger) were reported to affect insect pests via oviposition deterrent, insect repellent and antifeedant activities (Suthisut et al., 2011). These three species were common in Malaysia and widely planted especially as cooking condiments and medicinal use.

Most Zingiberaceae studies were demonstrated on several insect orders from Diptera, Lepidoptera, and Coleoptera. Zingiberaceae was tested in several forms, such as raw plant materials, plant extract, and essential oils (EOs). EOs are complex mixtures of volatile organic compounds produced as secondary metabolites in aromatic plants. EOs is volatile, natural, and characterized by strong odor (Bakkali et al., 2008). Insecticidal plants usually contain EOs with specific odor and flavor, like secondary metabolites that beneficial as a defense mechanism against pests. Pure compounds or blends of several major chemical components in EOs found to be toxic to insects. Although EOs performed lesser than insecticides, herbicides, or chemical repellents (Isman, 2008); they have been managed to execute insecticidal actions such as adverse developmental and reproductive effects, repellent, and feeding deterrence. Currently, there is no report in Malaysia on the potential use of Zingiberaceae plants in managing cocoa pests, particularly the $C$. cramerella. Therefore, the objective was to focus on the effects of three Zingiberaceae EOs as an adult emergence inhibition of the $C$. cramerella. The inhibition was determined by the percentage of the unhatched pupa, and adult deformities at four body parts; abdomen, antenna, wings, and overall body

\section{Materials and Methods}

The study was conducted at the Malaysian Cocoa Board, Cocoa Research and Development Center (CRDC) Bagan Datuk (3.906 N, 100.866 E), Perak, Malaysia. Zingiberaceae EOs were purchased from a local authorized dealer in Malaysia. Bioassay test was performed where EOs were diluted into four concentrations (100, 200, 400, and $800 \mathrm{ppm})$. Nonionic surfactant, Polyoxyethylene (20) sorbitan monooleate (Tween 80) was added, and the concentration was vortexed for 1-2 minutes at $1800 \mathrm{rpm}$. Control was prepared using the same amount of Tween 80 with addition water up to $100 \mathrm{ml}$. Concentrations were prepared 24 hours in advance, stored in dark amber glass bottle at $4^{\circ} \mathrm{C}$ before the experiment.

Mature cocoa pods with the symptoms of $C$. cramerella infestation was harvested, and destructive samplings were performed using approximately 200 to 300 cocoa pods to obtain a sufficient number of pupae. Pods were placed as a single layer in a large container and covered with dry cocoa leaves. Pupae were collected every 24 hours, daily and labelled based on their day after emergence (from Day-1 through Day-5), to confirm on their age before the treatment application. Pupae then were divided into an 
even number for each treatment, and EOs were sprayed at the distance of $15 \mathrm{~cm}$ using the hand sprayer. Pupae were left air-dried for two hours and kept in a transparent container. The number of successful emerging adults, deformed adults, and pupae were observed after 96 hours and onward. Pictorial data of the deformed adults and pupae were recorded using the Dino-Lite Digital Microscope. The experiment was repeated four times for each EOs. Data were arranged separately in Microsoft ${ }^{\circledR}$ Excel 2007 and were subjected to statistical analysis using Analysis of Variance (ANOVA) and PROC GLM, SAS software from the SAS® Software Version 8.

\section{Results and Discussion}

Effect of EOs on the developmental stage of $C$. cramerella denoted that regardless of different concentrations, $Z$. officinale shows the best performance when sprayed to Day-4 pupa (54.66 \%) and significantly different (One-Way ANOVA; $\mathrm{p}<0.05$ ) compared to other days (Table 1). Meanwhile, for $C$. longa, the highest mean of unhatched pupa was recorded at Day-3 (68.33\%) and significantly different from Day-1 (21.00\%), Day-2 $(42.00 \%)$, Day-4 (60.00\%) and Day-5 (23.33\%). Days$1(48.00 \%)$ and $2(48.00 \%)$ performed at the best age to spray with A. galanga. For all EOs, Days-5 recorded the lowest percent of the unhatched pupa, and this might suggest that older or matured pupa have high potential to survive, compared to the younger age of pupa. This study was not undertaken to more than Days-5 old pupa, because the probability of pupa emergence of an adult will be higher. At different concentrations, all EOs performed better than control (Table 2), which resulted in a significant percentage of the unhatched pupae.

Table 1. Percentage of the unhatched pupa of C. cramerella after treated at different age of pupa

\begin{tabular}{lcccc}
\hline \multirow{2}{*}{ Age of pupa } & Number observed & \multicolumn{3}{c}{ Unhatched pupa of C. cramerella (\%) } \\
\cline { 3 - 4 } & & Zingiber officinale & Curcuma longa & Alpinia galanga \\
\hline Day 1 & 20 & $43.11 \mathrm{~b}$ & $21.00 \mathrm{e}$ & $48.00 \mathrm{a}$ \\
Day 2 & 20 & $33.91 \mathrm{~d}$ & $42.00 \mathrm{c}$ & $48.00 \mathrm{a}$ \\
Day 3 & 20 & $33.33 \mathrm{~d}$ & $68.33 \mathrm{a}$ & $40.00 \mathrm{~b}$ \\
Day 4 & 20 & $54.67 \mathrm{c}$ & $60.00 \mathrm{~b}$ & $30.00 \mathrm{c}$ \\
Day 5 & 20 & $20.00 \mathrm{e}$ & $23.33 \mathrm{~d}$ & $24.00 \mathrm{~d}$ \\
\hline
\end{tabular}

Means followed by the same letter at vertical rows shows no significant difference at $p \geq 0.05$

Table 2. Percentage of unhatched pupa of C. cramerella after treated at different concentrations of Zingiberaceae EOs

\begin{tabular}{|c|c|c|c|c|}
\hline \multirow{2}{*}{ Treatment } & \multirow{2}{*}{ Number observed } & \multicolumn{3}{|c|}{ Unhatched pupa of C. cramerella (\%) } \\
\hline & & Zingiber officinale & Curcuma longa & Alpinia galanga \\
\hline $\mathrm{T} 1$ (100 ppm) & 20 & $44.05 \mathrm{~b}$ & $48.33 \mathrm{c}$ & $48.00 \mathrm{~b}$ \\
\hline $\mathrm{T} 2(200 \mathrm{ppm})$ & 20 & $33.00 \mathrm{~d}$ & $48.66 \mathrm{~b}$ & $40.00 \mathrm{c}$ \\
\hline T3 (400 ppm) & 20 & $49.48 \mathrm{a}$ & $55.00 \mathrm{a}$ & $52.00 \mathrm{a}$ \\
\hline $\mathrm{T} 4$ (800 ppm) & 20 & $37.38 \mathrm{c}$ & $47.00 \mathrm{~d}$ & $52.00 \mathrm{a}$ \\
\hline T5 (Control) & 20 & $21.11 \mathrm{e}$ & $15.67 \mathrm{e}$ & $4.00 \mathrm{~d}$ \\
\hline
\end{tabular}

Means followed by the same letter at vertical rows shows no significant difference at $p \geq 0.05$

Table 3. Percentage of the unhatched pupa and adult emergence of $C$. cramerella after treated at different age of pupa using Zingiberaceae essential oils

\begin{tabular}{|c|c|c|c|c|}
\hline \multirow{2}{*}{ Age of pupa } & \multirow{2}{*}{ Number observed } & \multicolumn{3}{|c|}{ Unhatched pupa of C. cramerella $(\%)$} \\
\hline & & Unhatched pupa & Healthy adult & Deformed adult \\
\hline Day 1 & 60 & $37.30 \mathrm{~b}$ & $42.67 \mathrm{c}$ & $19.96 \mathrm{a}$ \\
\hline Day 2 & 60 & $41.30 \mathrm{~b}$ & $45.59 \mathrm{~b}$ & $13.11 \mathrm{~b}$ \\
\hline Day 3 & 60 & $47.22 \mathrm{a}$ & $41.94 \mathrm{~d}$ & $10.83 \mathrm{~b}$ \\
\hline Day 4 & 60 & $50.22 \mathrm{a}$ & $38.56 \mathrm{~d}$ & $11.22 \mathrm{~b}$ \\
\hline Day 5 & 60 & $22.44 \mathrm{c}$ & $61.78 \mathrm{a}$ & $15.78 \mathrm{ab}$ \\
\hline
\end{tabular}

Means followed by the same letter at vertical rows shows no significant difference at $p \geq 0.05$ 
Inhibitory effect of Zingiberaceae essential oils against $C$. cramerella

Table 4. Percentage of adult emergence of $C$. cramerella after treated with different Zingiberaceae EOs

\begin{tabular}{|c|c|c|c|c|}
\hline \multirow{2}{*}{ Age of pupa } & \multirow{2}{*}{ Number observed } & \multicolumn{3}{|c|}{ Unhatched pupa of C. cramerella $(\%)$} \\
\hline & & Unhatched pupa & Healthy adult & Deformed adult \\
\hline Zingiber officinale & 80 & $40.98 \mathrm{c}$ & $46.98 \mathrm{~b}$ & $12.04 \mathrm{c}$ \\
\hline Curcuma longa & 80 & $49.75 \mathrm{a}$ & $35.08 \mathrm{c}$ & $15.17 \mathrm{~b}$ \\
\hline Alpinia galanga & 80 & $48.00 \mathrm{~b}$ & $34.00 \mathrm{~d}$ & $18.00 \mathrm{a}$ \\
\hline Control & & $13.59 \mathrm{~d}$ & $75.78 \mathrm{a}$ & $10.63 \mathrm{~d}$ \\
\hline
\end{tabular}

Means followed by the same letter at vertical rows shows no significant difference at $p \geq 0.05$

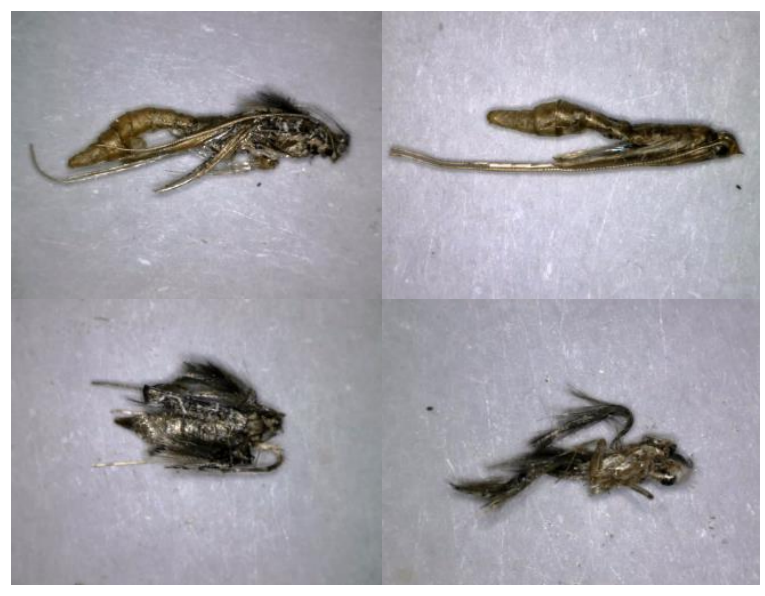

Fig. 1(A) Examples of unhatched pupae after the cocoon were removed $(30 x)$

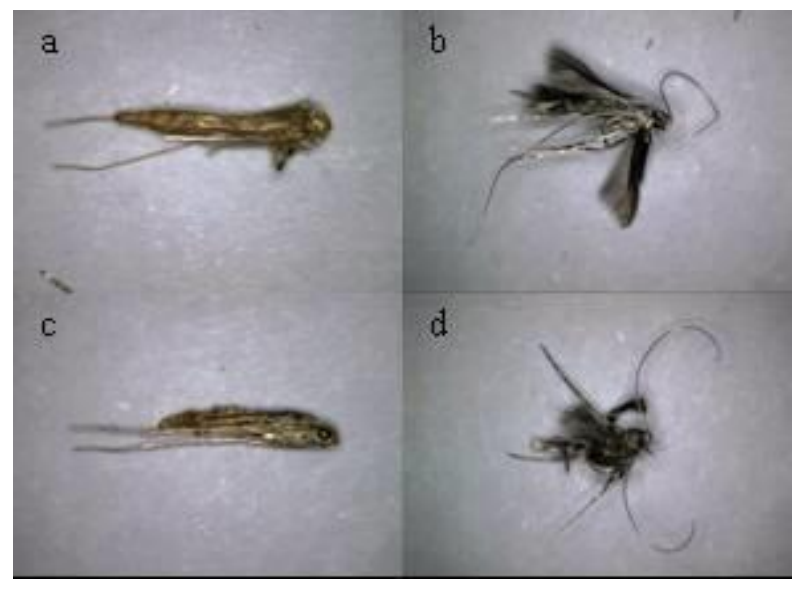

Fig. 1(B) Example of deformed adults a) abdomen, b) wings, c) antenna, and d) overall.

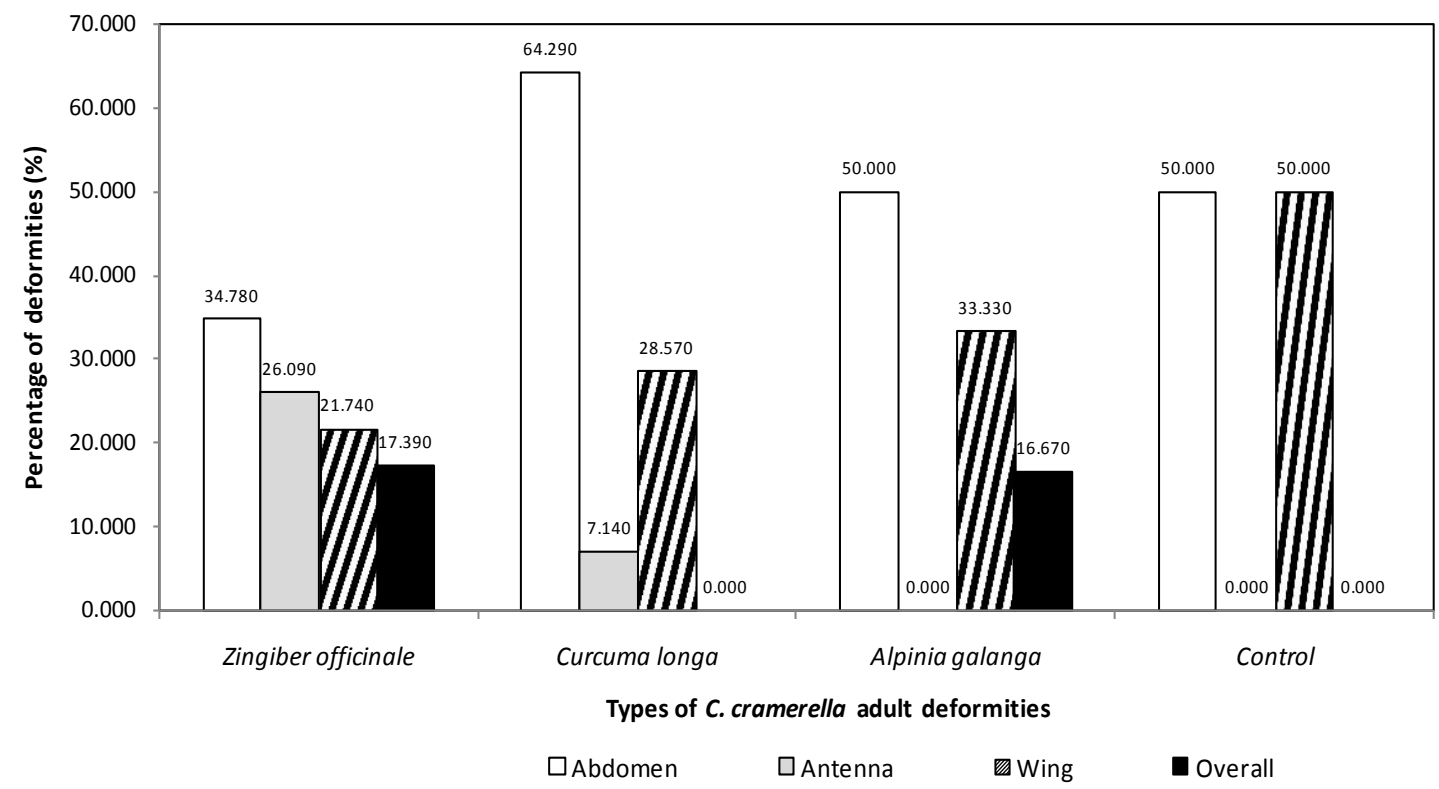

Fig. 2 Percentage of adult deformities of C. cramerella adult deformities after treated with different Zingiberaceae EOs 
In agreement as in the observation on the unhatched pupae (Table 1), Day-5 old pupae recorded the highest percentage of the successful emergence of a healthy adult $(61.77 \%$ a) after treating with Zingiberaceae ( $Z$. officinale, C. longa and A. galanga) treatments, and significantly different to other days (Table 3). Meanwhile, observation of the deformed adults, spraying of treatments at the young age of the pupa (Day-1) may result in the highest percentage of deformed adults (19.96 $\%$ a). This might occur during early development of cocoon, this newly established cocoon was still fragile, soft, and the most exposed to the treatments applied or any environmental factor. Control treatments recorded the highest percent of healthy adults $(75.777 \%$ a), and significantly different (One-Way ANOVA; p<0.05) compared to other EOs (Table 4). The lowest percentage of healthy adult emergence was recorded at A. galanga $(34.00 \% \mathrm{~d})$, followed by $C$. longa $(35.08 \% \mathrm{c})$ and $Z$. officinale $(46.98 \%)$. A. galanga performed as the best EOs which recorded the highest percentage of deformed adults $(18.00 \%)$ and significantly different (One-Way ANOVA; $<<0.05)$ with C. longa $(15.167 \%)$, Z. officinale $(12.04 \%)$ and the control treatment $(10.63 \%)$.

Adult deformities were observed at four different parts; the body (abdominal parts), the antenna, wings and the overall deformed (Figures 1A and 1B). Deformity of the abdominal part of $C$. cramerella was commonly observed and recorded the highest for all treatments (Figure 2). All four types of deformities only can be observed from $Z$. officinale, whereas no overall deformities observed for $C$. longa and control. Even the percentage of $C$. cramerella adult deformities were lower compared to the healthy adult, but all EOs shows promising results, where managed to deter the emergence of an adult from pupa stages as recorded in this study. Application of Zingiberaceae as potential botanical pesticides is an advantage because they are not labeled as poisonous, as well as dangerous to the environment and human health (Isman, 2008). Several species of Zingiberaceae produce EOs with chemical components that lead to pesticide mode of action. The mode of action of EOs is either in the form of direct contact or through ingestion. Saripah et al. (2019) reported on the pupation preference of $C$. cramerella where their study denoted that pupation on cocoa pods was lower compared to cocoa leaves regardless of different treatments through 10-days of observation. This might suggest on $C$. cramerella escapism strategy, where the pre-pupa try to hinder to pupate on the treated pods. Insidious characteristics of $C$. cramerella larva inside the pod for their entire instars, leaving the only egg, pupa, and adult as targeted life cycle to be controlled, as this study concentrated on the pupa stage.

During pupa developmental stages, the pupa will change color from an initial light green to dark gray as they mature, which takes six to eight days. In most cases, the deformed pupa can be seen even without removing the cocoons, when the pupa turned to entire dark gray or black. In this study, the percentage of the unhatched or the deformed pupa were higher for all Zingiberaceae EOs, with the range from $33.00 \%$ to $55.00 \%$ (Table 2) of the deformed pupa were observed. Unhatched pupa can be observed higher in the concentration of more than 400 ppm. This result shows that all EOs have the potential to disrupt the development process of adult emergence. The highest percentage of healthy adult with more than $75 \%$ was observed emerging from pupa at control treatment (75.77 \%; Table 4) comparisons to pupa exposed to EOs. Healthy adult of $C$. cramerella was characterized by a live adult emergence, which usually with a wing expanse of $10-14 \mathrm{~mm}$. The fore wing of a healthy adult has distal third except for costa pale orange-yellow. The basal marked with a zigzag pattern of six irregularly space transverse white lines partially edged with black. C. cramerella head is white with the crown roughened posterior and mixed or overlaid with fuscous. The antenna is white, scape suffused with fuscous dorsally, flagellum with indistinct fuscous annular bars dorsally to the near apex (Bradley, 1986). The antenna is about one and three-fifths length of the fore wing. This small, complete, and delicate structure of this gracillariid micro-moth usually unseen in deformed adults. The percentage of adult deformities were the lowest at control $(10.63 \%)$, and significantly different compared to other EOs. A. galanga recorded the highest percentage of adult deformities $(18.00 \%)$ with the abdominal deformity at $50.00 \%$ (Figure 2). Percentage of abdominal deformities were the highest for all Zingiberaceae EOs, compared to wings, antenna, and overall deformities.

\section{Conclusion}

The study has demonstrated the potential use of Zingiberaceae EOs as an adult emergence inhibition from a pupa to an adult will reduce the number of healthy adults and the number of ovipositing eggs later on. Deformities and adult emergence inhibition have strongly suggested that the mode of action of EOs could be through contact as an application of EOs was carried out at pupa stages. Selected Zingiberaceae species, Z. officinale, C. longa, and A. galanga that used in this study are safer for both human and environmental health. Thus, spraying with biopesticide formulation derived from Zingiberaceae EOs could help in reducing the population of $C$. cramerella in the near future, either as a single tool or as a part of an integrated pest management strategy.

\section{Acknowledgments}

Authors want to thank the Director General of MCB, Datin Norhaini Udin, the Director of Upstream Technology, Mr. Haya Ramba, and technical assistance provided by the staffs of Entomology Unit MCB Bagan Datuk, Mr. Ahmad Zaki Yusoff, Mr. Abdul Mutalib Abd. Kadir and Mr. Mohamad Faiz Yahya. MCB provided funding for this research under Temporary Research Fund (L15288). 


\section{References}

Alias, A. 2011. Resistance mechanisms in cocoa to cocoa pod borer. PhD Thesis. University of Reading. University of Reading.

Azhar, I. 1990. Post-harvest management of the cocoa pod borer (Lepidoptera: Gracillariidae). MARDI Research Journal, 18: 71-80.

Bakkali, F., Averback, S., Averback, D. and Idaomar, A. 2008. Biological effects of essential oils - A review. Food and Chemical Toxicology, 46: 446-475. https://doi.org/10.1016/j.fct.2007.09.106

Bradley, J.D. 1986. Identity of the South-East Asian cocoa moth, Conopomorpha cramerella (Snellen) (Lepidoptera: Gracillariidae), with descriptions of three allied new species. Bulletin of Entomological Research, 76: 41-51. https://doi.org/10.1017/S000748530001525X

Lee, C.H., Kelvin, L., Haya, R., Navies, M. and Saripah, B. (eds.) 2013. Cocoa planting manual. Sustainable cocoa. Malaysian Cocoa Board, Kota Kinabalu, Sabah, Malaysia.

Isman, M. B. 2008. Perspective botanical insecticides: for richer, poorer. Journal of Pest Management Science, 64: 8-11. https://doi.org/10.1002/ps.1470

Parkash, A. and Rao, J. 1997. Botanical pesticides in agriculture. CRC Lewis Publication, Boca Raton, USA.

Saripah, B. 2012. Cocoa Pod Borer Conopomorpha cramerella Snellen (Lepidoptera: Gracillariidae) infestation under shade and control treatments. Master thesis, Universiti Putra Malaysia. p. 174
Saripah, B. 2014. Control of Cocoa pod borer using insecticides and Cocoa black ants. Malaysian Cocoa, 8: 14-22.

Saripah, B and Alias, A. 2016. Evaluation of best management practices for cocoa pod borer in cocoa ecosystem. Malaysian Cocoa Journal, 9(1): 108-120.

Saripah Bakar, M.L.S. Noor Hajjar, A. Alias and A. Zhang, 2019. Pupation Preference of Conopomorpha Cramerella (Snellen) after Treated with Zingiber officinale, Curcuma longa and Alpinia galanga Essential Oils. Journal of Engineering and Applied Sciences, 14: 6150-6155. https://doi.org/10.3923/jeasci.2019.6150.6155

Suthisut, D., Fields, P. G. \& Chandrapatya, A. 2011. Fumigant toxicity of essential oils from three Thai plants (Zingiberaceae) and their major compounds against Sitophilus zeamais, Tribolium castaneum and two parasitoids. Journal of Stored Products Research, 47: 222-230. https://doi.org/10.1016/j.jspr.2011.03.002

Tounou, A. K., Mawussi, G., Amadou, S., Agboka, K., Gumedzoe, Y., Mawuena, D. \& Sanda, K. 2011. Bio-insecticidal effects of plant extracts and oil emulsions of Ricinus communis L. (Malpighiales: Euphorbiaceae) on the diamondback, Plutella xylostella L. (Lepidoptera: Plutellidae) under laboratory and semi-field conditions. Journal of Applied Biosciences, 43: 2899-2914.

Wohlmuth H. 2008. Phytochemistry and pharmacology of plants from the ginger family Zingiberaceae, Doctoral dissertation's thesis, Southern Cross University, Lismore, New South Wales 